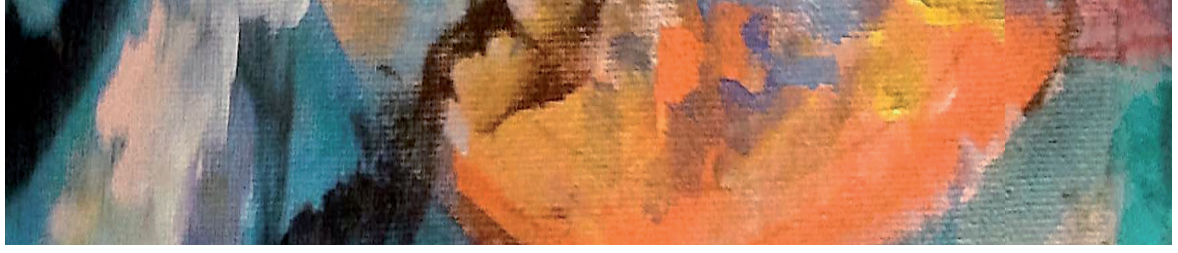

Entreculturas 11 (2021) pp. 85-104 — ISSN: 1989-5097

\title{
LA FORMACIÓN EN TRADUCCIÓN EN MÉXICO: DOCUMENTACIÓN Y ANÁLISIS DE LOS PROGRAMAS DE ESTUDIO
}

\author{
Translation Training in Mexico: \\ Documentation and Analysis of Study Programs \\ Héctor Libreros Cortez \\ (1) María del Pilar Ortiz Lovillo \\ Universidad Veracruzana (México)
}

Recibido: 13 de julio de 2020

Aceptado: 28 de septiembre de 2020

Publicado: 27 de febrero de 2021

\begin{abstract}
This article analyses the translation training scenario in Mexico. Emphasis is placed on the localization and study of translation programs and related areas, for example, undergraduate and graduate degrees in languages. This qualitative and explanatory case study is based on didactics of translation and educational research. Data analysis was carried out using a variety of information about different programs of Mexican public and private institutions. The results show the diversity in translation training in Mexico and its opportunity areas.
\end{abstract}

KEYWORDS: training, translation, languages, teaching, learning.
RESUMEN

En el presente artículo se analiza el escenario de la formación en traducción en México. Se hace énfasis en la localización y el estudio de los programas de estudios de traducción y áreas afines, por ejemplo, las licenciaturas y posgrados en lenguas. En este estudio de caso cualitativo y explicativo se emplea literatura especializada en didáctica de la traducción e investigación educativa. El análisis de los datos se llevó a cabo con el apoyo de la información obtenida de diversos programas de distintas instituciones mexicanas públicas y privadas. Los resultados evidencian la diversidad de la formación en traducción en México y sus áreas de oportunidad.

PALABRAS CLAVE: formación, traducción, lenguas, enseñanza, aprendizaje. 


\section{LA FORMACIÓN EN TRADUCCIÓN EN MÉXICO}

Entreculturas 11 (2021) pp. 85-104

\section{INTRODUCCIÓN}

En este artículo se presentan resultados parciales de dos investigaciones sobre la enseñanza y el aprendizaje de la traducción en México. La primera de ellas hace énfasis en la adquisición de la competencia traductora en estudiantes mexicanos y culminó en el año $2019^{1}$. La segunda investigación ${ }^{2}$ se encuentra en proceso y se tiene planeado que concluya en 2023. Este último estudio tiene como objetivo analizar la construcción de los saberes en traducción en estudiantes mexicanos que aprenden a traducir del inglés y francés al español. Al recabar la documentación pertinente para las investigaciones antes señaladas se logró identificar la escasa existencia de información sobre la formación en traducción en México, lo cual nos motivó a emprender una búsqueda detallada que nos proporcionara pistas para comprender, en mayor medida, la situación de la enseñanza y el aprendizaje de la traducción en el país. En específico, reflexionar sobre la presencia, la ausencia y la distribución de programas vinculados con la formación traductológica mediante un trabajo descriptivo centrado en un panorama situado.

\section{LA PRESENCIA DE LA TRADUCCIÓN EN LAS UNIVERSIDADES}

La traducción es una práctica que ha permitido la comunicación entre culturas desde tiempos remotos, por lo tanto, ha sido de gran relevancia para el progreso de la sociedad. Delisle y Cloutier (1995) señalan que esta actividad lingüís-

1 Para más información véase Libreros, H. (2019). La adquisición de la competencia traductora en la Facultad de Idiomas de la Universidad Veracruzana. (Tesis de maestría inédita) Instituto de Investigaciones en Educación, Universidad Veracruzana. México. Recuperado de https:// www.uv.mx/iie/files/2019/04/Tesis_Hector-LC-_-15.03.19.pdf

2 Se trata de una investigación doctoral intitulada La construcción de los saberes en la traducción: el caso de la Universidad Autónoma de Querétaro, la cual inició en agosto de 2019 y se lleva a cabo en la Universidad Veracruzana, México y la Universidad de Amberes, Bélgica. En ella se trabajan aspectos relacionados con la enseñanza-aprendizaje de la traducción en México centrados en un caso particular. tico-cultural surgió a la par de la escritura y la historia. Es decir, sus orígenes son milenarios. No obstante, la instauración de recintos académicos especializados en traducción es relativamente reciente. Caminade (1995) indica que la enseñanza y el aprendizaje en traducción e interpretación en Europa del Este se remite a las décadas de 1940 y 1950. Posterior a estas fechas, la formación en traducción muestra un incremento significativo que perdura hasta el año 2000.

Por su parte, Tricás (2003) señala que los espacios para la formación de traductores datan de mediados del siglo XX y surgen de la necesidad de contar con traductores profesionales. Por otro lado, el Libro blanco, Título de Grado en Traducción e Interpretación de la Agencia Nacional de Evaluación de la Calidad y Acreditación (ANECA) (2004) considera que la creación de instituciones centradas en la formación en este campo de estudios se vincula con la II Guerra Mundial y el aumento de traducciones fue posterior a este hito histórico.

En esta misma línea, Hurtado (2019: 4), durante el Foro Internacional sobre Estudios de Traducción e Interpretación organizado por la Universidad Veracruzana, indicó que los primeros recintos académicos orientados a la traducción e interpretación fueron: "Heidelberg (1930), Ginebra (1941), Moscú (1942), Viena (1943), Graz (1946), Insbruck (1946), Germesheim (1947), Saarbrucken (1948), Washington (1949), Trieste (1954), París (1949, 1957)”. Cabe agregar que, en España, la primera institución orientada a la enseñanza y aprendizaje de la traducción fue el Instituto Universitario de Lenguas Modernas y Traductores de la Universidad Complutense de Madrid, el cual fue fundado en 1974 (ANECA, 2004; Centro Virtual Cervantes, s.f.).

Por otro lado, en América Latina, también se crearon instituciones orientadas a la formación en traducción. Ortiz (2017: 75) reconoce que estos centros datan del siglo XX y se establecieron en: “Argentina (1945), Uruguay (1954), México (1966), Cuba (1968), Chile (1971) y Venezuela (1974), los cuales fueron seguidos por otros en países como Colombia, Costa Rica y Guatemala, amén de los muchos fundados en Brasil”. No obstante, el artículo de este autor no proporciona mayores detalles sobre dichos recintos académicos, lo cual impide explorar el establecimiento y desarrollo de estos espacios educativos. 
En la misma secuencia, Durieux (2005) examina la enseñanza y el aprendizaje de la traducción en múltiples centros a nivel global e identifica dos tipos de traductores, los primeros cuentan con estudios universitarios en traducción con una duración de entre 4 y 5 años y son altamente aptos para un empleo calificado. Por otro lado, están los otros, de los cuales no proporciona detalles. Se interpreta que estos traductores carecen de las cualificaciones provenientes del sistema educativo.

En relación con el punto anterior, Pym (2012) registra tres niveles de formación en traducción que presenta ciertas similitudes con la propuesta de Durieux (2005). El primero, hace referencia a un aprendizaje empírico, puesto que una gran cantidad de traductores se ha formado de esta manera, dada la carencia de educación formal en traducción. El segundo nivel, se relaciona con la formación mediante cursos cortos de traducción ${ }^{3}$, con una duración de 6 meses a 1 año, mientras que el último nivel, se centra en programas que tienen una mayor extensión, por ejemplo, las licenciaturas y maestrías. Este tipo de programas se remite, en su mayoría, a mediados del siglo XX; no obstante, alcanzan su auge a finales de la década de 1980 e inicios de 1990 (Caminade, 1995; Pym, 2012).

En la actualidad, las licenciaturas y posgrados en traducción se encuentran presentes en distintas partes del mundo y resultan de utilidad para trazar una línea académica y/o laboral. Meinster (2016) apunta a que los estudiantes de traducción durante su formación desarrollan una identidad útil para el campo profesional. Por su parte, Durieux (2005) permite identificar que la escuela de traducción influye en el desarrollo profesional del futuro traductor, puesto que algunas instituciones se encuentran mayormente orientadas a realizar determinados tipos de traducción. Esto a su vez, se relaciona con el contexto y las necesidades del país o la ciudad en cuestión.

3 Al respecto, Angeletti (2012: 2) "indica que el objetivo de muchos de estos cursos cortos y talleres radica en el entrenamiento y no en la educación. Cubren un conjunto vasto de temas que van desde el uso de una aplicación de software específico hasta la manera de ejercitar la propia memoria."

\section{EL ENTRAMADO METODOLÓGICO}

La metodología de la investigación es cualitativa y se encuentra orientada a describir y explicar la situación que ocurre en un contexto geográfico situado. Con base en lo anterior, se reconoce que el trabajo es un estudio de caso explicativo (Baxten y Jack 2008; Yin, 2003). El muestreo empleado fue no probabilístico, intencional (López, 2004). La atención se centró en distintos planes de estudio y mallas curriculares de determinados programas orientados de forma directa o parcial a la traducción, algunos de ellos habían sido identificados previamente en Libreros (2019). Sin embargo, se descubrieron nuevos programas de estudio. El análisis se centró en identificar y estudiar:

1. Las licenciaturas y posgrados en traducción;

2. Las licenciaturas y posgrados en lenguas extranjeras, lingüística y campos afines, con líneas o áreas de especialización en traducción y/o con cursos de traducción;

3. La presencia de la traducción en las universidades interculturales;

4. Los diplomados en traducción.

Para lograr lo anterior se tomaron en consideración a las universidades públicas federales; las universidades públicas estatales y las universidades interculturales que dependen de la Subsecretaría de Educación Superior (SES) de la Secretaría de Educación Pública (SEP) ${ }^{4}$, dado que estos espacios formativos cuentan con áreas académicas en Humanidades y/o Ciencias Sociales, que a su vez albergan facultades, institutos, colegios o departamentos, algunos de ellos especializados en lenguas nacionales y/o extranjeras y traducción.

Asimismo, se consultaron los portales oficiales de distintas instituciones de educación superior privadas, dependencias gubernamentales, asociaciones civiles, entre otras. Cabe mencionar que determinadas universidades públicas y priva-

4 Esta secretaría se encuentra encargada de la educación del país. Véase https://www.gob.mx/sep 


\section{LA FORMACIÓN EN TRADUCCIÓN EN MÉXICO}

Entreculturas 11 (2021) pp. 85-104

das no muestran información detallada sobre sus programas de estudio, su estructuración y cursos, razón por la cual no fueron consideradas en el estudio. Esto abre la posibilidad de contar con mayor presencia de la traducción en el país.

Por otro lado, es importante resaltar que el presente artículo concibe la construcción y no la recolección de los datos, esto con base en la postura teórico-metodológica de Diaz de Rada (2011: 283-284) que indica que "los datos no se recogen, se producen [...] porque es el investigador con sus procedimientos [...], quien les confiere existencia”. A partir de reflexionar en lo anterior, se reconoce que la construcción de los datos se llevó a cabo mediante el diálogo y la confrontación de tres puntos: 1 . La información recolectada; 2. La teoría proveniente de la didáctica de la traducción y 3. Los datos existentes sobre la formación traductológica en México.

\section{LA TRADUCCIÓN EN LAS UNIVERSIDADES EN MÉXICO}

En el contexto mexicano, la documentación de determinados programas de traducción y lenguas y/o literatura, que cuentan con estudios en traducción, ha sido expuesta en las investigaciones de Basich (2012); Ortiz y Figueroa-Saavedra (2014); Sánchez-Borzani (2018); Valdez-Gutiérrez $(2018)^{5}$ y Villegas-Salas (2019). Estos trabajos resultan de gran utilidad para trazar, en cierta medida, un panorama de la enseñanza y el aprendizaje de la traducción en la República Mexicana. En ellos, se puede apreciar la labor de instituciones públicas y privadas por la formación traductológica. No obstante, al revisar estas propuestas teórico-metodológicas y al contar con datos provenientes de Libreros (2019) se descubrió que la presencia de la traducción en los recintos académicos de México es aún más diversa y posee ciertas particularidades, las cuales se presentan a continuación.

5 Durante la realización del presente artículo se encontró la investigación intitulada El traductor en Baja California de Valdez-Gutiérrez (2018), en la cual se abordan los programas de licenciatura y posgrado en traducción. De igual manera, los programas de lenguas extranjeras en el país, puntos análogos del presente estudio, con los cuales se ha podido realizar una comparación de información.

\subsection{Los programas de traducción en las univer- sidades públicas en México}

Los Estados Unidos Mexicanos poseen una vasta extensión geográfica, se encuentran conformados por 31 estados y su capital, la Ciudad de México (CDMX). Cada una de estas entidades federativas cuenta con universidades públicas, algunas de ellas tienen un carácter estatal y otras uno federal. De igual forma, existen otros recintos académicos, ya que el país posee una amplia gama de instituciones de educación superior (IES). No obstante, a pesar de lo anterior solo se identificaron dos licenciaturas en traducción en universidades públicas en el país y se encuentran en la Universidad Autónoma de Baja California (UABC), que se ubica en el norte de la República Mexicana, y en la Universidad Nacional Autónoma de México $(\mathrm{UNAM})^{6}$, que tiene su campus central en CDMX.

El programa de la UABC es pionero en la enseñanza y aprendizaje de la traducción en México a nivel licenciatura. Esta universidad contó en 1991 con un programa técnico en traducción inglés-español y a partir de 1996 con una licenciatura en traducción (UABC, 2019; ValdezGutiérrez, 2018), la cual perdura, de forma exitosa, hasta la actualidad. De acuerdo con Valdez-Gutiérrez (2018) esta licenciatura es la que posee mayor demanda, a nivel estatal, en la Facultad de Idiomas de la UABC. Esta autora señala que, durante el primer semestre de 2018, la institución contaba con 775 estudiantes inscritos a este programa educativo en tres sedes: Mexicali con 189; Tijuana con 401; y Ensenada con 185. Asimismo, reconoce el aumento de la matrícula, puesto que, en el segundo semestre del año 2012, el programa contaba con un total de 366 estudiantes distribuidos en los tres campus antes señalados (Cfr. Valdez-Gutiérrez, 2018).

6 Esta universidad es la más grande e importante del país. Cuenta con presencia en distintos puntos de México, así como en el extranjero. De acuerdo con el ranking QS World University Rankings 2021 se posiciona en el lugar número 100 de las mejores universidades del mundo. Cfr. https://www.topuniversities.com/university-rankings/world-university-rankings/2021 (Consultado el 30 de junio de 2020). 
La licenciatura en traducción de la UNAM es más reciente, ya que la aprobación del programa se llevó a cabo en 2017 (UNAM-ENALLT, 2018). Esta licenciatura se imparte en la Escuela Nacional de Lenguas, Lingüística y Traducción (ENALLT) que se encuentra en el campus de Ciudad Universitaria en la CDMX. En 2020, la Extensión San Miguel de Allende de la Escuela Nacional de Estudios Superiores (ENES) Unidad León de la UNAM, ubicada en el estado de Guanajuato ha ofertado por vez primera esta licenciatura.

De manera similar, el número de posgrados en instituciones públicas también es reducido, ya que solo se cuenta con una especialidad y tres maestrías. La Especialidad en Traducción e Interpretación de la UABC data de 2009 (UABC, 2019) y la Maestría en Traducción del Colegio de México (COLMEX) de 2004. Esta última tiene como antecedente el Programa para la Formación de Traductores (PFT) que tuvo generaciones de 1974 a 2004 (CELL-COLMEX, 2012). Cabe agregar que el PFT brindó a una gran cantidad de personas la oportunidad para convertirse en traductores profesionales.

Por otro lado, también se encuentran la Maestría en Traducción e Interpretación de Lenguas Indígenas y la Maestría en Lengua, Literatura y Traducción, ambas pertenecientes a la Universidad Autónoma Benito Juárez de Oaxaca (UABJO). Estos programas son aún más recientes en comparación con los antes señalados. El primero de ellos preparó su convocatoria de inscripción en 2019 (UABJO, 2019a) mientras que el segundo inició clases en agosto del mismo año (UABJO, 2019b). Es decir, la primera generación está próxima a egresar.

Cabe añadir que, Valdez-Gutiérrez (2018) señalaba que hasta ese periodo en México no se contaba con programas de doctorado en traducción, situación que no ha cambiado en la actualidad ni siquiera en las universidades privadas; lo cual podría considerarse como un área de oportunidad para las IES con facultades, institutos y/o centros de investigación orientados al campo lingüístico y traductológico.

La información antes proporcionada permite identificar que las licenciaturas y maestrías en traducción del país son literalmente recientes. Su temporalidad se ajusta, en cierta medida, a lo ya expuesto por Caminade (1995) y Pym (2012) respecto al incremento de programas de traducción en 1980 y 1990. Si bien, la formación pública en traducción en México tiene como antecedente el PFT del COLMEX que data de 1974 (CELL-COLMEX, 2012); la primera licenciatura ofertada por una universidad pública se logra hasta 1996 (UABC, 2019).

Como se ha señalado con anterioridad, los programas de traducción de orden público en el país son pocos, se podría mencionar que su auge se alcanza hasta los años 2000, por lo tanto, se espera que en las próximas décadas siga en ascenso. A continuación, se muestra una tabla que presenta los programas de traducción antes señalados.

TABLA 1. Programas en traducción en IES públicas en México. Elaboración propia con base en la información de las IES antes señaladas

\begin{tabular}{cccc}
\hline $\begin{array}{c}\text { ENTIDAD } \\
\text { FEDERATIVA }\end{array}$ & IES & LICENCIATURA & POSGRADO \\
\hline Baja California & UABC & Licenciatura en Traducción & Especialidad en Traducción e Interpretación \\
\hline CDMX & UNAM & Licenciatura en Traducción & Maestría en Traducción \\
\cline { 2 - 4 } & COLMEX & & Maestría en Traducción e Interpretación de Lenguas Indígenas \\
Guanajuato & UNAM & Licenciatura en Traducción & Maestría en Lengua, Literatura y Traducción \\
\hline Oaxaca de Juárez & UABJO & & \\
\end{tabular}




\section{LA FORMACIÓN EN TRADUCCIÓN EN MÉXICO}

Entreculturas 11 (2021) pp. 85-104

Ortiz y Figueroa (2014) reconocieron, hace seis años, que la CDMX y el estado de Jalisco, específicamente Guadalajara, eran puntos centrales en la formación y titulación en traducción en el país. No obstante, estos autores contemplaron solo a determinadas IES públicas y privadas de México. Como se muestra en la tabla 1, el presente estudio logró identificar que los programas de traducción pertenecientes a las IES públicas están concentrados en cuatro zonas clave del país: Baja California, CDMX, Oaxaca y San Miguel de Allende, Guanajuato. Uno de los puntos afines entre estos lugares es la necesidad de la comunicación en diferentes lenguas nacionales y/o extranjeras y la traducción, ya sea por política, turismo, educación y comercio, por mencionar algunos.

Es importante comentar que el estado de Baja California conserva una relación constante con los Estados Unidos de América, específicamente con California. De este modo, la integración de las economías conlleva una necesidad de traducción profesional que la universidad intenta satisfacer. La interacción entre estos espacios geográficos es social, política, económica y lingüística, incluso podría identificarse la existencia de una realidad bicultural en Tijuana, la ciudad con mayor población e índice de cruces migratorios en Baja California (Valdez-Gutiérrez, 2018).

Por otro lado, la CDMX es el centro financiero, político y académico del país. Asimismo, es una de las ciudades más pobladas del mundo. De acuerdo con Fernández-Acosta (2018: 16) quien trabajó en la Encuesta nacional del perfil del traductor en México ${ }^{7}$ señala que:

Nuestro estudio muestra que 56\% (268 traductores)
reside en la Ciudad de México, capital política, ad-
ministrativa y económica del país. 6\% (30) reside en
Jalisco, donde se encuentra la sede del capítulo de
Occidente de la Organización Mexicana de Traduc-
tores (OMT) y otro 6\% (30) en el Estado de México;
4\% en Nuevo León (19) y otro 4\% (17) en Baja Ca-

7 Esta encuesta recabó información de 477 traductores que residen en la República Mexicana. lifornia Norte, donde en 2005 se crea e imparte la primera licenciatura en traducción en una universidad pública (UABC); 3\% en Querétaro (16).

Esta información se relaciona con lo ya señalado por Ortiz y Figueroa-Saavedra (2014) sobre la importancia de la CDMX y de Guadalajara en torno a la formación en traducción en la República Mexicana. Fernández-Acosta (2018) añade que, en estas dos grandes ciudades, así como en Monterrey y Toluca, se concentra la mayor cantidad de firmas dedicadas a la traducción en el país. Cabe subrayar que Toluca y Ciudad de México pertenecen a la zona metropolitana del Valle de México.

En otro orden de ideas, Oaxaca es un estado ampliamente reconocido por su cultura y diversidad étnica. Kleinert y Stallaert (2018: 13-14) indican que esta entidad federativa "ocupa el primer lugar a nivel nacional de hablantes de lenguas indígenas con un total de 1 millón 227 mil 660 según el conteo intercensal de 2015”. Sin embargo, la investigación de estas autoras permite reconocer que todavía existe trabajo por realizar en torno a la traducción e interpretación en lenguas indígenas, ya que señalaban que hasta el año 2018 no había "centros permanentes donde se ofrezcan formaciones para intérpretes y traductores de lenguas indígenas nacionales” (Kleinert y Stallaert, 2018: 25), lo cual cambió en el año 2019 con la Maestría en Traducción e Interpretación de Lenguas Indígenas de la UABJO. Sin embargo, es necesario tener presente la importancia de implementar licenciaturas en traducción e interpretación en lenguas extranjeras y nacionales en esta zona del país.

Por otra parte, se encuentra San Miguel de Allende que, como se señaló anteriormente cuenta con la licenciatura en traducción más reciente de la República Mexicana. Esta ciudad del estado de Guanajuato es uno de los puntos turísticos más destacados de la nación y desde 2008 fue nombrada Patrimonio Mundial de la Humanidad por la UNESCO (SECTUR, 2015).

Para finalizar este apartado es necesario subrayar que además de los programas en traducción de la UABC no se encontraron otras licenciaturas o posgrados en traducción en las IES públicas en otros estados fronterizos del nor- 
te o del sur del país, aunque dos de los países vecinos de México, Belice y los Estados Unidos de América, utilizan el inglés en la comunicación cotidiana. Valdez-Gutiérrez (2018) identificó distintos programas públicos y privados en lenguas extranjeras en estados de la frontera norte: Chihuahua, Coahuila, Nuevo León, Sonora y Tamaulipas. Sin embargo, solo una de estas licenciaturas cuenta con una orientación en traducción e interpretación y se oferta en una institución privada en Tamaulipas. Un panorama similar ocurre en el sur del país, punto que se abordará a mayor profundidad más adelante al analizar los programas en lenguas extranjeras.

\subsection{Los programas de traducción en universidades privadas en México}

La situación de la enseñanza y el aprendizaje de la traducción en IES privadas no es muy diferente al contexto de la educación pública. Ortiz y Figueroa-Saavedra (2014); Sánchez-Borzani (2018); Valdez-Gutiérrez (2018) y Villegas-Salas (2019) enuncian determinados programas pertenecientes a la iniciativa privada en sus investigaciones; el presente artículo coincide con estos autores en algunas licenciaturas y posgrados en traducción. No obstante, se añaden nuevos programas presentes en distintos puntos del país.

En el estudio se identificaron una licenciatura en traducción, una licenciatura en interpretación y cuatro licenciaturas con énfasis en traducción e interpretación. De igual forma, tres especialidades y tres maestrías. Lo cual permite reconocer un panorama, un poco más amplio en comparación con las IES públicas. Asimismo, una presencia más marcada de la formación en interpretación y la existencia de programas centrados en determinadas áreas de los estudios de la traducción, por ejemplo, la terminología y la traducción técnica. A continuación, se presenta una tabla que muestra mayores detalles de lo antes señalado.

TABLA 2. Programas en traducción en IES privadas en México. Elaboración propia con base en la información de las IES antes señaladas

\begin{tabular}{|c|c|c|c|}
\hline ENTIDAD & IES & LICENCIATURA & POSGRADO \\
\hline \multicolumn{4}{|l|}{ FEDERATIVA } \\
\hline \multirow{6}{*}{ CDMX } & Instituto Superior de Interpretes y & Licenciatura en Traducción & Especialidad en Terminología \\
\hline & Traductores (ISIT) & Licenciatura en Interpretación & Especialidad en Traducción \\
\hline & Universidad Tecnológica Americana & Licenciatura en Interpretación y Traducción & Técnica \\
\hline & (UTECA) & Licenciatura en Traducción, Localización e & \\
\hline & Universidad Intercontinental (UIC) & Interpretación & \\
\hline & $\begin{array}{l}\text { Sistema Harvard Educacional SC } \\
\text { (SHE) }\end{array}$ & Licenciatura en Interpretación y Traducción & \\
\hline \multirow[b]{2}{*}{ Morelos } & Angloeducativo Centro de Idiomas & Licenciatura en Traducción e Interpretación & Especialidad en Traducción \\
\hline & & del Inglés & Técnica Inglés-Español \\
\hline \multirow[b]{2}{*}{ Jalisco } & Universidad Autónoma de Guadalajara & & Maestría en Traducción e Inter- \\
\hline & (UAG) & & pretación Inglés-Español \\
\hline \multirow[b]{2}{*}{ Puebla } & Universidad Madero Puebla (UMAD) & & Maestría en Interpretación y \\
\hline & & & Traducción \\
\hline & Tecnología Turística Total & & Maestría en Competencias \\
\hline Yucatán & A. C. (TTTAC) & & Traductoras \\
\hline
\end{tabular}




\section{LA FORMACIÓN EN TRADUCCIÓN EN MÉXICO}

Entreculturas 11 (2021) pp. 85-104

Como se puede observar en la tabla anterior, la CDMX tiene la oferta más diversificada y es posiblemente el único espacio geográfico del país que cuenta con licenciaturas en traducción tanto en la educación pública como privada. Situación que no ocurre con el resto de las entidades federativas, ya que los estados con programas de traducción en IES privadas no son los mismos que aquellos con programas de traducción en IES públicas, por lo tanto, podría intuirse que las universidades privadas subsanan la carencia principalmente de posgrados en traducción en determinados puntos del país. Sin embargo, incluso si se toman en consideración los programas de universidades públicas y privadas varios estados de la República Mexicana siguen sin contar con licenciaturas y posgrados en traducción. A continuación, se muestra una figura que ilustra lo antes señalado.

FIGURA 1. Programas de traducción en México. Elaboración propia

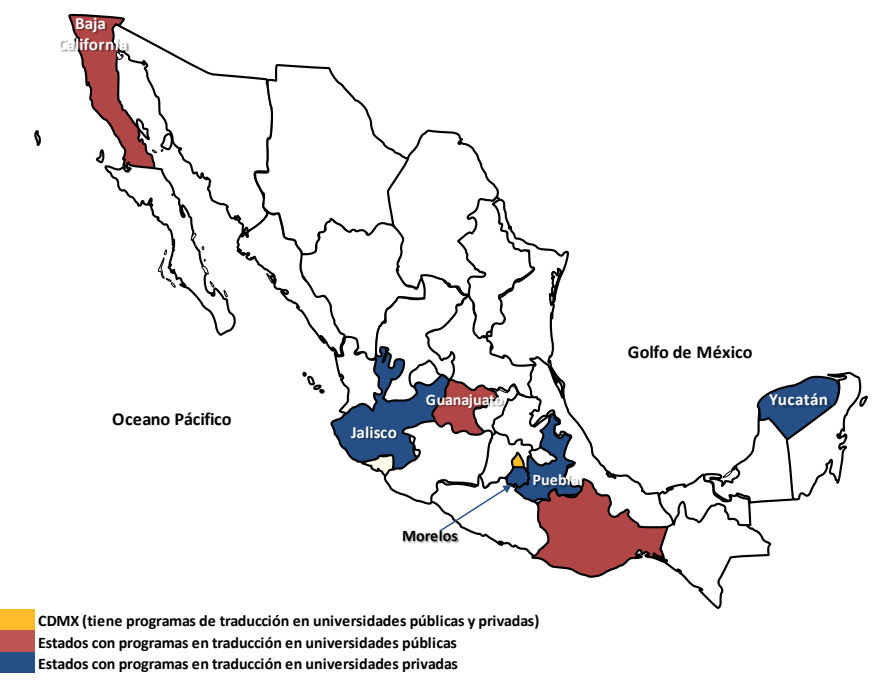

La figura 1 permite identificar que los programas de traducción en IES públicas y privadas se concentran en ocho de las 32 entidades federativas del país. Lo cual equivaldría a una cuarta parte del territorio nacional. Otro punto por resaltar es que además de no identificar programas de traducción en distintos estados fronterizos, tampoco se encontraron en determinados estados con alta demanda turística, por ejemplo: Baja California Sur, Nayarit, Guerrero y Quintana Roo. La figura anterior muestra algunos de los programas de formación en traducción en México; no obstante, la enseñanza y el aprendizaje de la traducción en la República Mexicana no se limita solo a estos programas, dado que se presentan en otros espacios universitarios, como se muestra a continuación.

\subsection{La traducción en programas del área de humanidades}

Como se ha mencionado con anterioridad, la formación en traducción en México no solo se lleva cabo en los programas de traducción. Ortiz y Figueroa-Saavedra (2014); Valdez-Gutiérrez (2018) y Villegas-Salas (2019) identifican que la enseñanza y el aprendizaje de la traducción se presenta en distintos programas en lenguas extranjeras y literaturas del país. El presente artículo coincide con estas investigaciones; no obstante, identificó que la traducción también se efectúa dentro de determinadas licenciaturas y posgrados públicos orientados a la lingüística e investigación educativa. La presencia es más marcada a nivel licenciatura. Sin embargo, en algunas maestrías y doctorados también cultivan la traducción mediante líneas de investigación o cursos de traducción (Véase Tabla 3).

A nivel licenciatura, la traducción se presenta de dos maneras: 1. Mediante cursos de traducción y 2. Como línea terminal o de especialización en un programa de lengua extranjera, literatura y/o lingüística aplicada. El análisis de la información permitió identificar que en 15 programas universitarios de determinadas IES públicas se enseña y aprende a traducir mientras que en siete IES públicas se cuenta con una línea terminal y/o especialización en traducción. Lo anterior se refleja de manera más explícita en la siguiente tabla. 


\section{Héctor Libreros Cortez y María del Pilar Ortiz Lovillo}

Entreculturas 11 (2021) pp. 85-104

TABLA 3. Programas de humanidades vinculados con la traducción.

Elaboración propia con base en la información de las IES antes señaladas

\begin{tabular}{|c|c|c|c|}
\hline ENTIDAD & IES & LICENCIATURA CON CURSOS EN & POSGRADO CON CURSOS EN \\
\hline \multirow[t]{2}{*}{ FEDERATIVA } & & TRADUCCIÓN (CT) Y/O UNA LÍNEA & TRADUCCIÓN (CT) Y/O UNA LÍNEA \\
\hline & & TERMINAL EN TRADUCCIÓN & $\begin{array}{c}\text { DE INVESTIGACIÓN DONDE SE } \\
\text { CULTIVA LA TRADUCCIÓN }\end{array}$ \\
\hline
\end{tabular}

\begin{tabular}{llll}
\hline Aguascalientes & $\begin{array}{l}\text { Universidad Autónoma de } \\
\text { Aguascalientes (UAA) }\end{array}$ & $\begin{array}{l}\text { Licenciatura en Docencia de Francés y } \\
\text { Español como Lenguas Extranjeras (CT) }\end{array}$ \\
\hline Baja & Universidad Autónoma de & Maestría en Lenguas Modernas (línea: Lin- \\
California & Baja California (UABC) & güística aplicada, discurso y sociolingüística) \\
& & Doctorado en Ciencias del Lenguaje (línea: \\
& & Lenguas, textos y contextos)
\end{tabular}

\begin{tabular}{lll}
\hline Campeche & $\begin{array}{l}\text { Universidad Autónoma del } \\
\text { Carmen (UNACAR) }\end{array}$ & $\begin{array}{l}\text { Licenciatura en Lengua Inglesa (con } \\
\text { especialización en Traducción) }\end{array}$ \\
\hline Chiapas & $\begin{array}{l}\text { Universidad de Ciencias y } \\
\text { Artes de Chiapas } \\
\text { (UNICACH) }\end{array}$ & $\begin{array}{l}\text { Licenciatura en Lenguas Internacionales } \\
\text { (con área de Traducción e Interpretación }\end{array}$ \\
\hline
\end{tabular}

\begin{tabular}{ll}
\hline Chihuahua & Universidad Autónoma de Licenciatura en Lengua Inglesa (CT) \\
& Chihuahua (UACH)
\end{tabular}

\begin{tabular}{|c|c|c|c|}
\hline \multirow[t]{2}{*}{ CDMX } & $\begin{array}{l}\text { Universidad Nacional } \\
\text { Autónoma de México } \\
\text { (UNAM) }\end{array}$ & $\begin{array}{l}\text { Licenciatura en Lengua y Literatura } \\
\text { Modernas (Inglesas, Francesas, Ale- } \\
\text { manas, Italianas y Portuguesas) (con } \\
\text { área en traducción) } \\
\text { Licenciatura en Literatura Intercul- } \\
\text { tural (CT) } \\
\text { Licenciatura en Letras Clásicas (CT) }\end{array}$ & $\begin{array}{l}\text { Maestría en Letras (Literatura Compa- } \\
\text { rada) (línea: Estudios de traducción) } \\
\text { Doctorado en Letras (línea: Traducción } \\
\text { y edición crítica de clásicos griegos y } \\
\text { latinos) } \\
\text { Maestría y Doctorado en Lingüística } \\
\text { (línea: Traducción literaria y estilística) }\end{array}$ \\
\hline & $\begin{array}{l}\text { Colegio de México } \\
\text { (COLMEX) }\end{array}$ & & $\begin{array}{l}\text { Doctorado en Lingüística (línea: Traduc- } \\
\text { ción, lingüística e interculturalidad) }\end{array}$ \\
\hline Durango & $\begin{array}{l}\text { Universidad Juárez del Esta- } \\
\text { do de Durango (UJED) }\end{array}$ & $\begin{array}{l}\text { Licenciatura en Docencia de la Lengua } \\
\text { Inglesa (CT) }\end{array}$ & \\
\hline $\begin{array}{l}\text { Estado de } \\
\text { México }\end{array}$ & $\begin{array}{l}\text { Universidad Autónoma del } \\
\text { Estado de México (UAEMéx) }\end{array}$ & $\begin{array}{l}\text { Licenciatura en Lenguas (con énfasis en } \\
\text { traducción del inglés y/o francés) }\end{array}$ & \\
\hline Guerrero & $\begin{array}{l}\text { Universidad Autónoma de } \\
\text { Guerrero (UAGro) }\end{array}$ & $\begin{array}{l}\text { Licenciatura en Enseñanza del idioma } \\
\text { Inglés (CT) }\end{array}$ & \\
\hline Jalisco & $\begin{array}{l}\text { Universidad de Guadalajara } \\
\text { (UdeG) }\end{array}$ & $\begin{array}{l}\text { Licenciatura en Didáctica del Francés } \\
\text { como Lengua Extranjera (CT) } \\
\text { Licenciatura en Docencia del Inglés } \\
\text { como Lengua Extranjera (CT) }\end{array}$ & $\begin{array}{l}\text { Maestría Interinstitucional en Deutsch als } \\
\text { Fremdsprache: Estudios Interculturales de } \\
\text { Lengua, Literatura y Cultura Alemanas (CT) } \\
\text { Maestría en Lingüística Aplicada (CT) }\end{array}$ \\
\hline
\end{tabular}




\section{LA FORMACIÓN EN TRADUCCIÓN EN MÉXICO}

Entreculturas 11 (2021) pp. 85-104

\begin{tabular}{|c|c|c|c|}
\hline Morelos & $\begin{array}{l}\text { Universidad Autónoma del } \\
\text { Estado de Morelos (UAEM) }\end{array}$ & $\begin{array}{l}\text { Licenciatura en Enseñanza del Francés } \\
\text { (CT) } \\
\text { Licenciatura en Enseñanza del Inglés } \\
\text { (CT) }\end{array}$ & \\
\hline Nuevo León & $\begin{array}{l}\text { Universidad Autónoma de } \\
\text { Nuevo León (UANL) }\end{array}$ & $\begin{array}{l}\text { Licenciatura en Lingüística Aplicada a la } \\
\text { Enseñanza y Traducción del Inglés } \\
\text { Licenciatura en Lingüística Aplicada a la } \\
\text { Enseñanza y Traducción del francés }\end{array}$ & \\
\hline Oaxaca & $\begin{array}{l}\text { Universidad Autónoma } \\
\text { Benito Juárez de Oaxaca } \\
\text { (UABJO) }\end{array}$ & & $\begin{array}{l}\text { Doctorado en Estudios Críticos del Len- } \\
\text { guaje (CT) }\end{array}$ \\
\hline Puebla & $\begin{array}{l}\text { Benemérita Universidad Au- } \\
\text { tónoma de Puebla (BUAP) }\end{array}$ & $\begin{array}{l}\text { Licenciatura en la Enseñanza del Inglés } \\
\text { (CT) } \\
\text { Licenciatura en la Enseñanza del Fran- } \\
\text { cés (CT) }\end{array}$ & \\
\hline Querétaro & $\begin{array}{l}\text { Universidad Autónoma de } \\
\text { Querétaro (UAQ) }\end{array}$ & $\begin{array}{l}\text { Licenciatura en Lenguas Modernas en } \\
\text { (Español, Inglés y Francés) con líneas } \\
\text { terminales en: Literatura y Traducción y } \\
\text { Lingüística y Traducción. }\end{array}$ & \\
\hline Tabasco & $\begin{array}{l}\text { Universidad Juárez Autóno- } \\
\text { ma de Tabasco (UJAT) }\end{array}$ & Licenciatura en Idiomas (CT) & \\
\hline Tamaulipas & $\begin{array}{l}\text { Universidad Autónoma de } \\
\text { Tamaulipas (UAT) }\end{array}$ & $\begin{array}{l}\text { Licenciatura en Idiomas Inglés (CT) } \\
\text { Licenciatura en Lingüística Aplicada } \\
\text { (CT) }\end{array}$ & \\
\hline Tlaxcala & $\begin{array}{l}\text { Universidad Autónoma de } \\
\text { Tlaxcala (UATx) }\end{array}$ & $\begin{array}{l}\text { Licenciatura en Enseñanza de Lenguas } \\
\text { (CT) }\end{array}$ & \\
\hline $\begin{array}{l}\text { Veracruz de } \\
\text { Ignacio de la } \\
\text { Llave }\end{array}$ & $\begin{array}{l}\text { Universidad Veracruzana } \\
\text { (UV) }\end{array}$ & $\begin{array}{l}\text { Licenciatura en Lengua Inglesa (CT) } \\
\text { Licenciatura en Lengua Francesa } \\
\text { (CT) } \\
\text { Licenciatura en Lengua y Literatura } \\
\text { Hispánicas (CT) }\end{array}$ & $\begin{array}{l}\text { Maestría y Doctorado en Investigación } \\
\text { Educativa (línea: Investigación Lingüística } \\
\text { y Didáctica de la Traducción) } \\
\text { Maestría en Didáctica del Francés (CT) } \\
\text { Maestría en Literatura Mexicana y Docto- } \\
\text { rado en Literatura Hispanoamericana (línea } \\
\text { Literatura: Creación y Traducción) } \\
\text { Doctorado en Estudios del Lenguaje y } \\
\text { Lingüística Aplicada (línea: Enseñanza- } \\
\text { aprendizaje de lenguas, temática traducción } \\
\text { e interpretación) }\end{array}$ \\
\hline
\end{tabular}




\begin{tabular}{lll}
\hline Yucatán & $\begin{array}{l}\text { Universidad Autónoma de } \\
\text { Yucatán (UADY) }\end{array}$ & $\begin{array}{l}\text { Licenciatura en Enseñanza del Inglés } \\
(\mathrm{CT})\end{array}$ \\
\hline Zacatecas & $\begin{array}{l}\text { Universidad Autónoma de } \\
\text { Zacatecas (UAZ) }\end{array}$ & $\begin{array}{l}\text { Licenciatura en Lenguas Extranjeras con } \\
\text { salida terminal en traducción. }\end{array}$ \\
\hline
\end{tabular}

Como se puede observar en la tabla 3, la traducción tiene mayor presencia en las IES públicas a través de distintos programas del área de humanidades que en licenciaturas y posgrados exclusivos en traducción. Cabe aclarar que algunas de las licenciaturas que se muestran en la tabla cuentan con una cantidad significativa de cursos y/o talleres en traducción mientras que algunas otras cuentan solo con una o dos asignaturas en esta área de estudios. Asimismo, algunas veces tienen un carácter obligatorio mientras que en otros casos son materias optativas. A continuación, se presenta una figura que muestra de una manera más distintiva los datos de la tabla.

FIGURA 2. La traducción en programas de humanidades. Elaboración propia

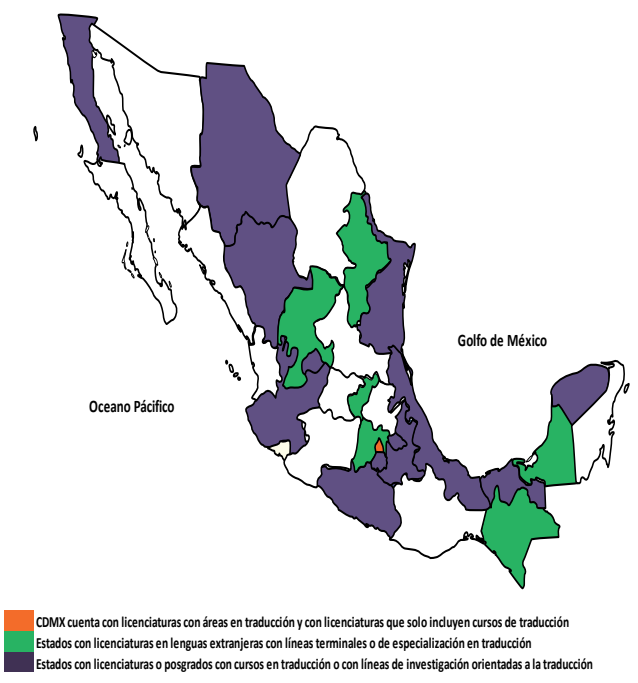

La figura anterior permite identificar que la distribución de la traducción no es uniforme, pero las regiones centro y sureste tienen mayor cantidad de estados con IES públicas donde se imparte la traducción. Si se incluyera en esta figura al estado de Oaxaca, entidad federativa que cuenta con dos programas en traducción, casi todas las universidades públicas del sureste y centro sur del país contempladas en el estudio tendrían un vínculo visible con la enseñanza y el aprendizaje de la traducción. Por otro lado, se debe señalar que la UANL es la única universidad estatal pública ubicada en la frontera norte que cuenta con licenciaturas con énfasis en traducción mientras que en la frontera sur la UNACAR y la UNICACH cuentan con este tipo de programas.

\subsection{La traducción en las universidades intercul- turales}

Hasta el momento se ha analizado la presencia de la traducción en distintas universidades federales, estatales y privadas. No obstante, dentro de la clasificación de IES de México proporcionada por la SES de la SEP también se encuentran las universidades interculturales que son instituciones públicas orientadas a la formación de la población rural e indígena del país, esta inclinación las hace diferentes del resto de las universidades antes presentadas. Sin embargo, "no se busca que las universidades sean exclusivamente para indígenas. Por el contrario, se favorece la experiencia intercultural que significa convivir con miembros de otras culturas indígenas y con la mestiza, y de la mestiza con ellos" (Schmelkes, 2008: 335). Es decir, estas IES apelan al contacto entre las culturas del país.

Estas universidades cuentan con programas de licenciatura cuyos planes de estudio son regularmente de cuatro años. De igual modo, poseen posgrados. Schmelkes (2008) permite reconocer que estas IES son de reciente creación, ya que la primera de ellas se fundó en 2003. Esta autora vincula el establecimiento de estos recintos académicos con tres cuestiones: “a) La escasa cobertura de la población indígena en la educación superior en general, y en la pú- 


\section{LA FORMACIÓN EN TRADUCCIÓN EN MÉXICO}

blica en particular. [...] b) Las demandas indígenas. [...] c) El desequilibrio geográfico del desarrollo nacional." (Schmelkes, 2008: 329) mientras que para Dietz y Mateos-Cortés (2019: 167-168) este tipo de universidades:

surgen con un doble encargo: por un lado, tienen como encomienda ampliar la cobertura de la educación superior pública hacia las regiones rurales y campesinas; [...] y por otro lado, se justifican por ofrecer carreras no convencionales y no-urbanocéntricas, sino que tengan una "pertinencia cultural y lingüística” en las regionales a las que atienden.
Dietz y Mateos-Cortés (2019) añaden que estas IES constituyen un nuevo subsistema universitario, donde se hace énfasis en la preservación y revitalización de las lenguas originarias de la República Mexicana. Sin embargo, reconocen la carencia de profesores con conocimientos en lenguas indígenas y de materiales didácticos suficientes en estos idiomas, entre otros. Los autores indican que la licenciatura en lengua y cultura es uno de los programas básicos de las universidades interculturales. Con esto en mente, el presente estudio decidió revisar este programa y otros afines en las universidades interculturales enlistadas por la SES y tratar de rastrear la presencia de la formación en traducción en lenguas originarias. A continuación, se presenta una tabla que muestran mayores detalles al respecto.

TABLA 4. La traducción en las universidades interculturales. Elaboración propia con base en la información de las IES antes señaladas

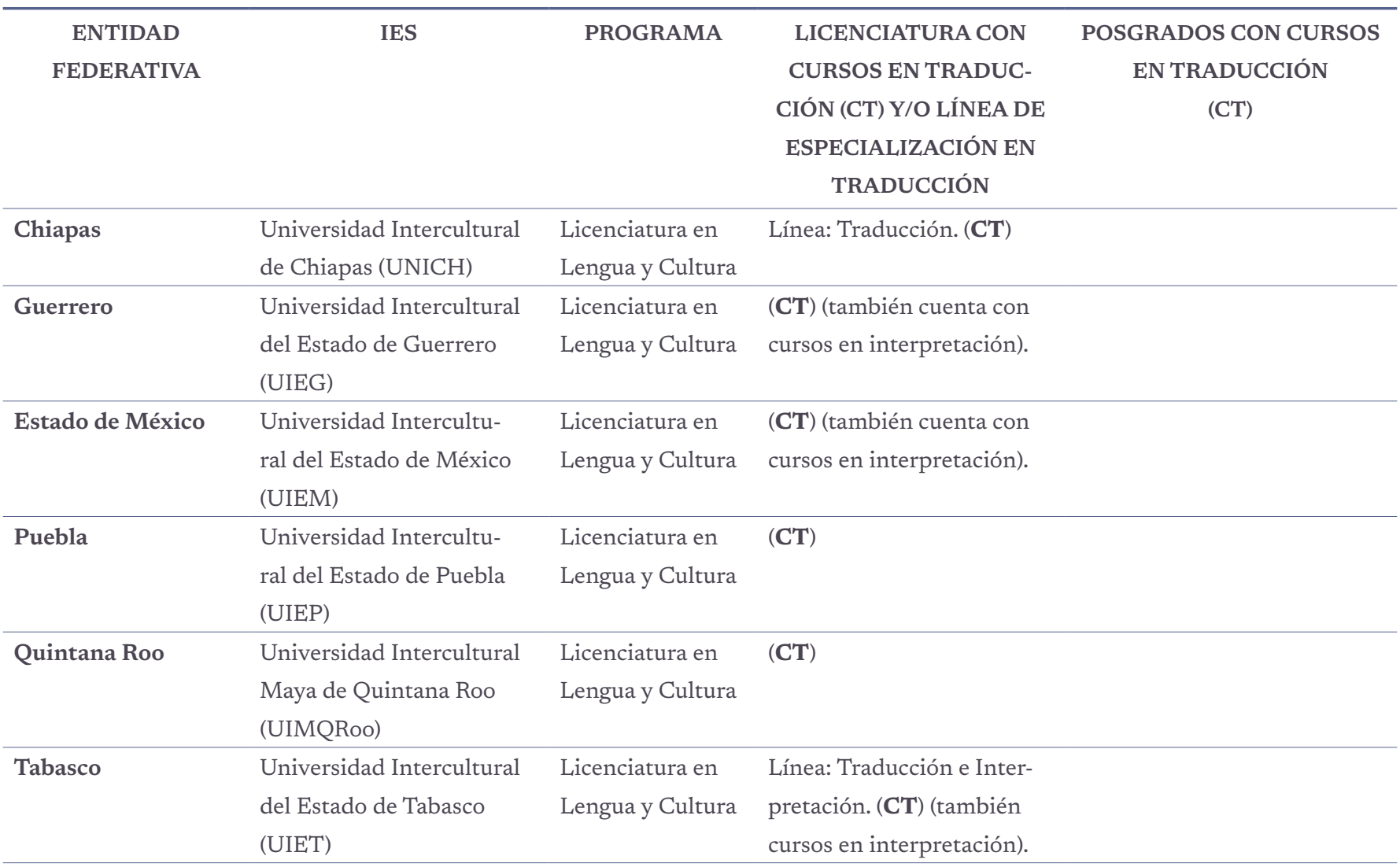




\begin{tabular}{clll}
\hline Veracruz de Ignacio & Universidad Intercultural & Licenciatura & Maestriah ipan Totlahtol iwan \\
de la Llave & Veracruzana (UVI) ${ }^{9}$ & en Gestión & Tonemilis/Maestría en Lengua \\
& & Intercultural para & y Cultura Nahua (CT) \\
& el Desarrollo & \\
\hline
\end{tabular}

Como se puede observar el número de universidades interculturales analizado es pequeño, dado que no todas las entidades federativas de la República Mexicana cuentan con este tipo de instituciones. Asimismo, porque algunas de estas IES no despliegan suficiente información sobre sus programas de estudio. Por lo tanto, se intuye que la formación traductológica en lenguas originarias en el país podría ser más amplia. Cabe agregar que muy pocas universidades interculturales presentan su información en lengua(s) originarias (s) y en español, lo cual contrasta con la idea de fortalecer y revitalizar las lenguas nacionales. A continuación, se presenta un mapa que ejemplifica la presencia de la traducción en estas IES.

FIGURA 3. La traducción en las universidades interculturales.

\section{Elaboración propia}

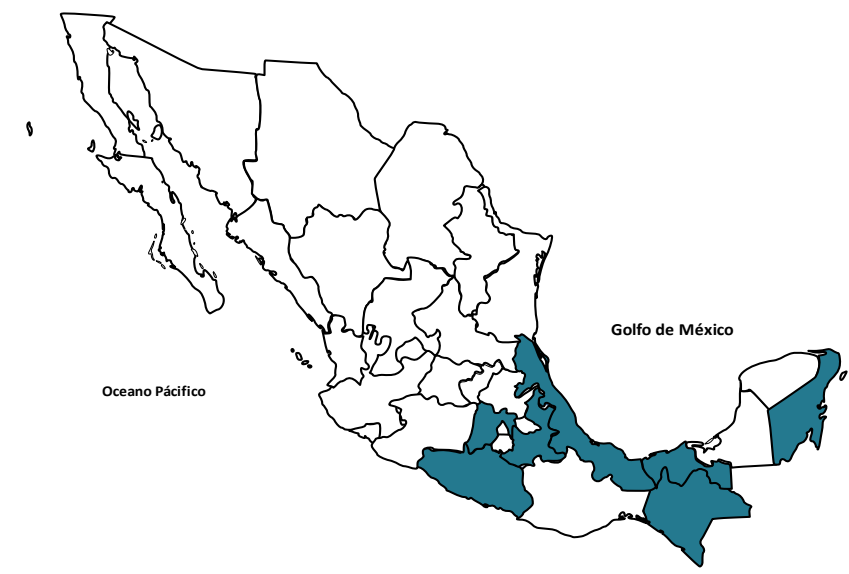

Estados con universidades interculturales que cultivan la traducción

9 Esta universidad es una dependencia de la Universidad Veracruzana, Máxima Casa de Estudios del estado de Veracruz, el resto de las instituciones mostradas en la tabla sí se despliegan en la clasificación de universidades interculturales de la Subsecretaría de Educación Superior de la SEP.
La traducción en las universidades interculturales está mayormente presente mediante cursos y en menor medida en líneas de especialización mientras que a nivel posgrado la presencia es mínima. En relación con este punto, es importante señalar la poca existencia de programas orientados exclusivamente a la traducción en lenguas originarias en la República Mexicana, puesto que solo se identificó la Maestría en Traducción e Interpretación de Lenguas Indígenas de la UABJO, la cual ostenta el título de universidad estatal y no de universidad intercultural.

Por otro lado, la situación de la interpretación no es muy distinta, dado que "los procesos de formación de intérpretes de lenguas indígenas-español son una dinámica emergente [...] y deben trascender e institucionalizarse adecuadamente. Sería recomendable, por lo tanto, fijar metas para la apertura de espacios de formación continua para los intérpretes" (Kleinert, 2006: 619). Aparte de los datos antes presentados en torno a la traducción en lenguas nacionales existen otras iniciativas relacionadas con estos idiomas, por ejemplo, la puesta en marcha de un proyecto internacional para que los mayahablantes indígenas puedan mejorar su acceso a la salud mediante la creación de materiales didácticos bilingües (Iglesias \& Tercedor, 2014). Asimismo, los diplomados en interpretación del Instituto Nacional de Lenguas Indígenas (INALI) los cuales "se identifican como el inicio de un proceso de profesionalización de los intérpretes” (Kleinert, 2006: 606). Estos se han puesto en marcha en distintos estados de la Republica Mexicana, por ejemplo: Guerrero, Puebla, Veracruz y Oaxaca, entre otros. (Kleinert, 2006). En el siguiente apartado se presentan más detalles sobre estos programas.

\subsection{Los diplomados en traducción e interpreta- ción en México}

La formación en traducción en México también se imparte mediante diplomados. Es importante explicar que un di- 


\section{LA FORMACIÓN EN TRADUCCIÓN EN MÉXICO}

Entreculturas 11 (2021) pp. 85-104

plomado es un programa de estudios que se organiza en módulos que comprenden determinados contenidos sobre diversas disciplinas, por ejemplo: didáctica de la traducción, traducción literaria, traducción especializada y traducción audiovisual, entre otros y tiene el propósito de actualizar conocimientos. No otorga grados académicos solo un comprobante de estudios que en México se llama Diploma. Se trata de cursos cortos que son impartidos por universidades y/o asociaciones civiles; su duración es regularmente de un semestre o un año de estudios. No obstante, esto puede variar, puesto que este tipo de programas se amolda a los lineamientos de las instituciones que los imparten. Es decir, ellos deciden el número de horas lectivas que conforma el diplomado, los horarios, los contenidos y las formas de evaluación, por mencionar algunos.

Un diplomado en traducción puede ser cursado por estudiantes de licenciatura y/o posgrado o, en ocasiones, por el público en general, esto depende de los requerimientos del programa en cuestión, donde los estudiantes reciben formación sobre un área específica del saber. Por lo general, dependiendo de cada institución, se solicita como requisitos de ingreso al diplomado los siguientes documentos: un curriculum vitae, una carta de exposición de motivos, contar con una certificación, como mínimo con un nivel B2 de la lengua de partida, además de un buen manejo del español, presentarse a una entrevista y pagar una inscripción. Al culminar de forma exitosa, el egresado recibe un diploma que acredita sus estudios en determinada disciplina, por ejemplo, traducción y/o interpretación. No obstante, este documento no confiere un grado académico.

Con base en lo antes expuesto y al retomar a Pym (2012), se podría afirmar que dada la naturaleza de los diplomados estos programas pertenecen al segundo nivel de formación en traducción. Al investigar sobre los diplomados en traducción, se identificó que tienen presencia en distintos puntos del país. No obstante, su localización es más compleja en comparación con las licenciaturas y posgrados, ya que al estar clasificados como formación continua en ocasiones su información es limitada y/o compartida mediante las redes sociales; sin embargo, existen IES y asociaciones civiles que cuentan con datos detallados sobre sus diplomados, motivo por la cual fueron contemplados en la investigación. Cabe añadir que se identificaron algunos programas que datan de hace cinco, diez o más años, pero existen muy pocos registros de ellos y de su continuidad en la actualidad, razón por la cual no fueron incluidos en el estudio. A continuación, se muestra una tabla que proporciona más detalles de los diplomados.

TABLA 5. Diplomados en traducción e interpretación. Elaboración propia con base en la información de las IES antes señaladas

\begin{tabular}{|c|c|c|c|}
\hline ENTIDAD & INSTITUCIÓN & TIPO DE & PROGRAMA \\
\hline FEDERATIVA & & INSTITUCIÓN & \\
\hline \multirow[t]{3}{*}{ Aguascalientes } & Universidad Autónoma & Pública & Diplomado en Traducción e Interpretación del Idioma \\
\hline & de Aguascalientes (UAA) & & Inglés \\
\hline & Universidad Nacional Autónoma & Pública & Diplomado en Traducción de Textos Especializados \\
\hline \multirow{6}{*}{ CDMX } & Universidad Iberoamericana de & Privada & Diplomado en Traducción (inglés-español) \\
\hline & Ciudad de México (IBERO) & & \\
\hline & Cámara Nacional de la Industria & Organismo & Diplomado en Traducción Literaria y Humanística \\
\hline & Editorial Mexicana (CANIEM) - & gremial- & \\
\hline & & & e Interpretación Profesional en línea \\
\hline & Sistema Educacional Harvard (SHE) & Privada & Diplomado de Traducción Jurídica \\
\hline
\end{tabular}




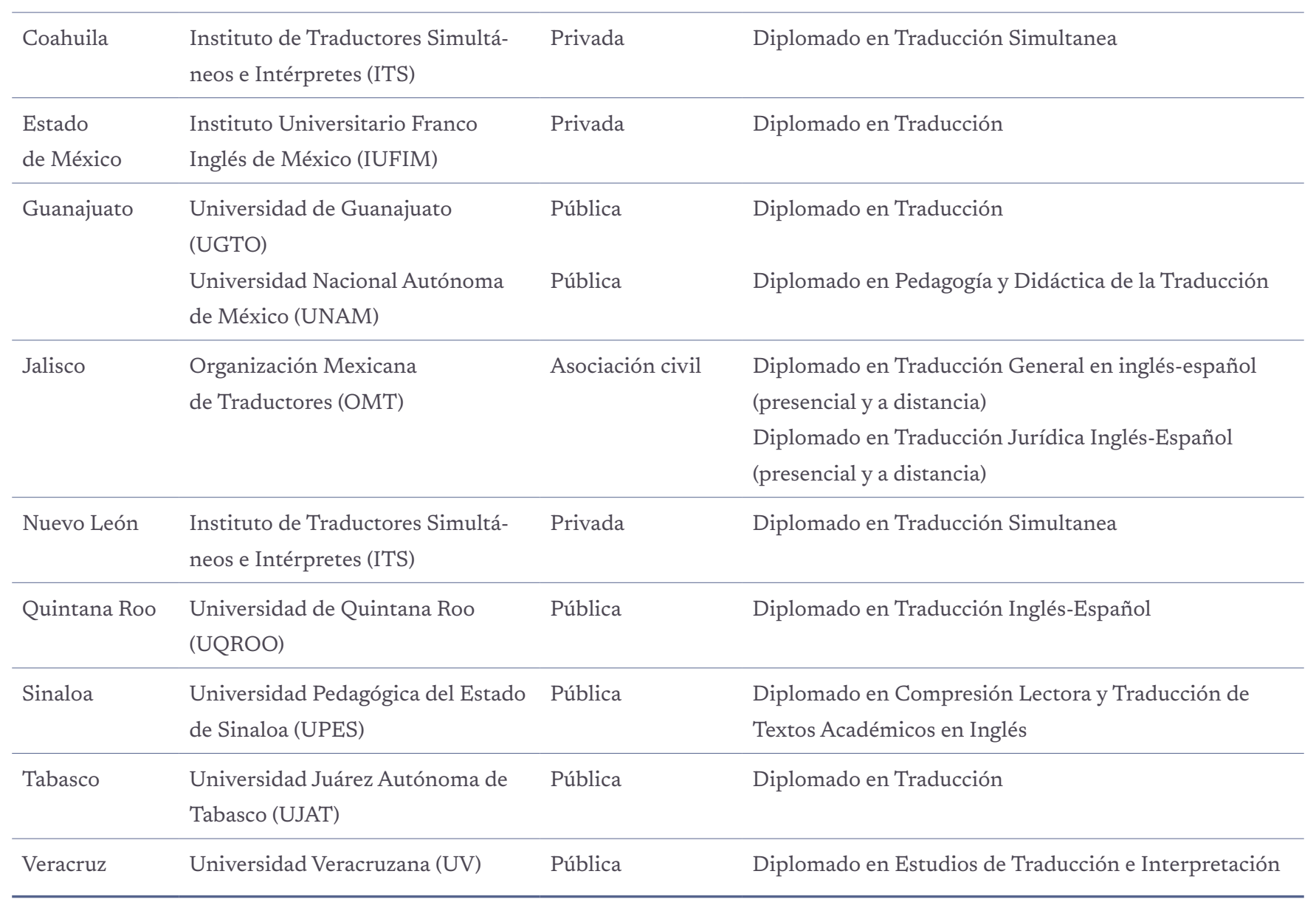

Los diplomados se centran en mayor medida en la traducción y algunos de ellos en la interpretación; otros se especializan en determinadas áreas de estudio, por ejemplo: la traducción literaria, jurídica, científica, por mencionar algunas. En cambio, otros brindan herramientas generales, teóricas y prácticas, para traducir y/o interpretar. En otras palabras, están orientados a formar traductores e intérpretes generalistas. No obstante, el punto en común de estos programas es profesionalizar a los estudiantes en los estudios de la traducción y/o interpretación con miras a que se desempeñen laboralmente en estas áreas de estudio o en algunas de sus subdisciplinas.

Es conveniente mencionar también que se cuenta con otros diplomados centrados en la interpretación para la justicia para indígenas, en ellos "confluyen hablantes de lenguas indígenas que cuentan con diversos grados de ex- periencia y perfiles educativos y que cabe catalogar como intérpretes prácticos o naturales" (Kleinert \& Stallaert: 238). Estos diplomados han sido de gran ayuda para la población originaria de México, ya que "hasta hoy, estos programas han formado a más de 500 intérpretes de lenguas nacionales registrados en el Padrón Nacional de Intérpretes y Traductores de Lenguas (PANITLI)." (Kleinert \& Stallaert: 238). Se ha optado por no incluirlos con gran detalle en este artículo por dos motivos, el primero de ellos es porque el presente documento hace énfasis en la formación en traducción y el segundo porque estos programas ya han sido ampliamente analizados por Kleinert y Stallaert (2014; 2015; 2016; 2017; 2018; 2019; 2020).

A continuación, se presenta una figura que ejemplifica la distribución de los diplomados en la República Mexicana. 


\section{LA FORMACIÓN EN TRADUCCIÓN EN MÉXICO}

Entreculturas 11 (2021) pp. 85-104

FIGURA 4. Los diplomados en traducción e interpretación. Elaboración propia

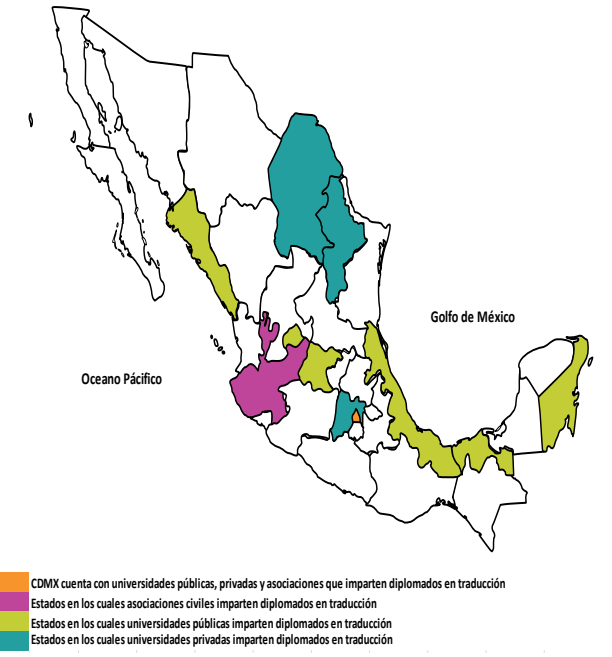

Como se puede observar en la figura anterior, los diplomados identificados en el estudio son pocos, aunque se consideren a las instituciones públicas y privadas. No obstante, enriquecen la formación en traducción en el país. Se intuye que estos programas subsanan, en cierta medida, la carencia de programas de posgrado en traducción general o especializada en distintos puntos de México. Asimismo, contribuyen a profesionalizar a los estudiantes provenientes de programas de lenguas extranjeras, literatura y/o lingüística, por mencionar algunos que desean convertirse en traductores y/o intérpretes. Resultaría interesante analizar la viabilidad de convertir estos diplomados en especialidades o maestrías que brinden a sus egresados un grado universitario y a su vez fortalezcan la formación en traducción en la República Mexicana.

Es importante señalar que los diplomados no son equivalentes a las licenciaturas, se trata de cursos cortos en traducción similares a los que señala Angeletti (2012) (véase Apartado 2), cuyo objetivo es brindar herramientas para profesionalizar al traductor o al futuro traductor. Asimismo, se asemejan a los training programs presentes en Estados Unidos, los cuales no son licenciaturas o posgrados, pero proveen con bases teórico-prácticas a las personas que aspiran a convertirse en traductores o intérpretes (Cabrera, 2017).
Para ejemplificar mejor la naturaleza de este tipo de formación, se retoma el Diplomado en Estudios de Traducción e Interpretación de la Universidad Veracruzana, el cual se llevó a cabo de agosto de 2018 a abril de 2019 y estuvo compuesto por diez módulos (cursos/talleres), de 30 horas cada uno, los cuales fueron: Estudios de traducción; Traducción y cultura; Estudios de interpretación; Traducción de textos humanísticos; Traducción de textos especializados, Traducción de textos literarios, Revisión y edición de textos, Herramientas de traducción, Prácticas de interpretación y Didáctica de la traducción. Cabe señalar que este diplomado contó con varios módulos, pero otros programas son más breves.

Las clases fueron impartidas por traductores e investigadores especializados en traducción y se llevaron a cabo los viernes de 4 a 20 hrs. y los sábados de 9 a 15 hrs. que sumaron en total trescientas horas lectivas. $\mathrm{Al}$ concluir todos los módulos de manera satisfactoria los estudiantes recibieron un diploma por parte del Instituto de Investigaciones en Educación de la Universidad Veracruzana que avala sus conocimientos básicos en traducción e interpretación. Este documento no les concede un grado académico, pero evidencia que ahora cuentan con nociones sobre el campo disciplinar.

\section{CONCLUSIONES}

La presencia de la traducción en el contexto mexicano es variada, ya que se manifiesta mediante licenciaturas, especialidades y maestrías en traducción en distintas IES públicas y privadas. Asimismo, en diferentes programas de lenguas y literaturas extranjeras y nacionales a través de cursos obligatorios y/u optativos o mediante líneas terminales o áreas de concentración. De igual forma, se cultiva en diplomados cuyo objetivo está orientado a profesionalizar a los estudiantes en los estudios de la traducción. Cabe reconocer que, de acuerdo con la información presentada, distintas entidades de la República Mexicana conservan un fuerte vínculo con la formación en traducción e interpretación. De la misma manera, determinadas universidades estatales tratan de enmendar la carencia de formación exclusiva en traducción. 
Pese a esto, es necesario continuar trabajando para fortalecer los espacios educativos donde se cultiva la traducción, es decir, las facultades de lenguas extranjeras e institutos centrados en investigaciones lingüísticas y educativas de las universidades federales y estatales, cuyo interés primario casi nunca es la actividad traductológica, así como a la Escuela Nacional de Lenguas, Lingüística y Traducción (ENALLT) de la Universidad Nacional Autónoma de México, única en su tipo en el país. Este reforzamiento tendría que comenzar con el reconocimiento a la labor traductológica en estas entidades académicas por parte de las mismas instituciones universitarias que en ocasiones la invisibilizan o minimizan. Además, es primordial que las instituciones interesadas en la traducción comiencen a tender puentes entre ellas para colaborar a nivel educativo y en la investigación. Asimismo, sería interesante que las universidades ubicadas en zonas fronterizas analizaran la viabilidad de desarrollar programas de traducción en lenguas nacionales y/o extranjeras y entablar diálogo con instituciones de los países vecinos, por ejemplo, Estados Unidos, Belice y Guatemala.

También es importante que las IES públicas que cuentan con licenciaturas y posgrados en traducción, es decir, la UABC, UABJO, COLMEX y la UNAM se identifiquen como punta de lanza y orienten a otras universidades para poner en marcha nuevos programas educativos en traducción e interpretación. Igualmente, mediante su amplia experiencia en la disciplina, podrían emprender trabajo colaborativo con otras IES para profesionalizar/actualizar mediante cursos cortos, talleres o posgrados presenciales o en línea a profesores de traducción y a traductores autodidactas que no han tenido la oportunidad de formarse dentro de los recintos académicos mexicanos. Por lo anterior, es necesario continuar con la difusión de la trascendencia de la traducción para el desarrollo social en la República Mexicana.

\section{REFERENCIAS BIBLIOGRÁFICAS}

ANECA (2004): Libro blanco, Título de Grado en Traducción e Interpretación. [En línea]:

https://www.ehu.eus/documents/1690128/1704927/
libro_blanco_Traduccion_Interpretacion_ANECA.pdf. [consulta: 11 de julio de 2020].

Angelelli, C. V. (2012): "Teaching translation and interpreting”, en Chapelle, C. A. (ed.): The encyclopedia of applied linguistics. USA, Blackwell Publishing Ltd.

Basich, Kora (2012): La formación de profesores en traducción. Reflexiones desde un caso mexicano. México, Universidad Autónoma de Baja California (UABC).

Baxter, P., y Jack, S. (2008): "Qualitative case study methodology: Study design and implementation for novice researchers", The Qualitative Report, 13, 544-559.

$B U A P$ [en línea] (s.f.): http://www.facultaddelenguas.com/ home. [consulta: 11 de julio de 2020].

Cabrera, T. (2017): The Translation and Interpreting Industry in the US. Observatorio Reports. Observatory of the Spanish Language and Hispanic Cultures in the US. Instituto Cervantes at Harvard University- FAS

CANIEM [en línea] (2020): http://www.caniem.org/es/capacitacion/diplomado-en-traducci\%C3\%B3n-literaria-yhuman\%C3\%ADstica. [consulta: 28 de junio de 2020].

Caminade, M. (1995): "Les formations en traduction et interprétation: Perspectives en Europe de l'Ouest”, TTR, 8, 247-270.

CELL-COLMEX [en línea] (2012): https://cell.colmex.mx/index.php/centrodeestudioslinguisticosyliterarios/historiacell. [consulta: 12 de junio de 2020].

CVC [en línea] (2020): https://cvc.cervantes.es/lengua/iulmyt/. [consulta: 10 de junio de 2020].

Delisle, Jean y Woodsworth, Judith (eds.): (1995). Translators through history. The Netherlands, John Benjamin Publishing Co.

Díaz de Rada, Ángel (2011): El taller del etnógrafo: Materiales y herramientas de investigación en Etnografía. Madrid, UNED.

Dietz, G. y Mateos-Cortés, L. S. (2019): "Las universidades interculturales en México, logros y retos de un nuevo subsistema de educación superior” Estudios sobre las Culturas Contemporáneas, 25, 163-190.

Durieux, C. (2005): “L'enseignement de la traduction: enjeux et démarches” Meta, 50, 36-47. 


\section{LA FORMACIÓN EN TRADUCCIÓN EN MÉXICO}

Entreculturas 11 (2021) pp. 85-104

ENES León-UNAM [en línea] (2019): https://enes.unam.mx/ traduccion.html. [consulta: 12 de junio de 2020].

Fernández-Acosta, L. R. (2018): “En busca del reconocimiento de la profesión del traductor en México”, en FernándezAcosta, L.R. (coord.): La profesión del traductor en México. Ciudad de México, UIC.

Grupo Educativo Angloeducativo S.C. [en línea] (s.f.): https:// angloamericano.com.mx/licenciaturas/. [consulta: 16 de junio de 2020].

Hurtado, A. (2019): La didáctica de la traducción. Foro Internacional sobre Estudios de Traducción e Interpretación UV. Xalapa.

IBERO Ciudad de México [en línea] (s.f.): https://www.diplomados.ibero.mx/Programas/Temario-de-Programa. aspx $? i d=20 \&$ nombre $=$ Traducci $\%$ C 3\%B3n $\% 20$ \%28Ingl\%C3\%A9s\%20-\%20Espa\%C3\%B1ol\%29\&idAre $\mathrm{a}=6$ \&tipo=Diplomado\&a\%C3\%B1o=2019\&version=1\&id Propuesta=216. [consulta: 11 de julio de 2020].

ISIT [en línea] (2011): http://www.isit.edu.mx/index.html. [consulta: 16 de junio de 2020].

ITS [en línea] (2018): http://traductoressimultaneos.com/ diplomado-en-traduccion-simultanea/. [consulta: 11 de julio de 2020].

IUFIM [en línea] (2020): https://iufim.com.mx/diplomadoen-traduccion/ . [consulta: 11 de julio de 2020].

Kleinert, C. (2014): “Didáctica para la formación de intérpretes en lenguas nacionales de México: trabajar de manera multilingüe", Entreculturas: revista de traducción y comunicación intercultural, 7, 599-624.

Kleinert, C. y Stallaert, C. (2015): “La formación de intérpretes de lenguas indígenas para la justicia en México. Sociología de las ausencias y agencia decolonial”. Sendebar, 26, 235-254.

Kleinert, C. (2016): Formación e iniciación profesional de intérpretes de lenguas nacionales mexicanas para la justicia: el caso de Puebla. Instituto de Investigaciones en EducaciónUniversidad Veracruzana/Facultad de Letras y Filosofía, Departamento de Lingüística Aplicada/Traducción e Interpretación-Universidad de Amberes. [cd-rom].

Stallaert, C. y Kleinert, C. (2017): “México y Bélgica: interpretación para la justicia en países multilingües vista a través del enfoque intercivilizacional y decolonial". Trans: revista de traductología (21), 211-226.

Kleinert, C. y Stallaert, C. (2018): "Una deuda histórica: formación de intérpretes para la justicia en oaxaca”, Transfer, 13, 13-29.

Kleinert, C. Núñez-Borja, C. y Stallaert, C. (2019): “Buscando espacios para la formación de intérpretes para la justicia en lenguas indígenas en América Latina" Mutatis Mutandis, (1), 78-99.

Stallaert, C. Núñez-Borja, C. y Kleinert, C. (2020): “Acceso a la justicia y formación de intérpretes en lenguas indígenas. Una propuesta de cooperación triangular con enfoque decolonial”. CPU-e, Revista de Investigación Educativa, (30), 60-83.

Libreros, H. (2019): La adquisición de la competencia traductora en la Facultad de Idiomas de la Universidad Veracruzana. Instituto de Investigaciones en Educación- Universidad Veracruzana. [cd-rom].

López, P. L. (2004): “Población muestra y muestreo”, Punto Cero, 09, 69-74.

Meinster, L. (2016): “Threshold concepts and ways of thinking and practising: the potential of a framework for understanding in translation didactics", The Interpreter and Translator Trainer, 11, 1-18.

$O M T$ [en línea] (s.f.): https://omt.org.mx/capacitacion/diplomado-en-traduccion-general. [consulta: 11 de julio de 2020].

Ortiz, J. (2017): “Los Estudios de Traducción y el mundo hispánico: conceptos y ubicación”, Matices en lenguas extranjeras, 10, 72-96.

Ortiz, M. P. y Figueroa-Saavedra, M. (2014): "Los estudios de traducción en la Universidad Veracruzana. Un camino sin final”, CPU-e. Revista de investigación Educativa, Número conmemorativo, 40 años del IIE, 80-98.

Carrillo, X. I., \& Sánchez, M. T. (2014): Acceso a la salud por parte de la población indígena mayahablante en México: elaboración de materiales didácticos desde la interculturalidad. Panace, 15(40), 235-242.

Pym, A. (2012): “Training Translators”, en Malmkjær, K. y Windle, K (eds): The Oxford Handbook of Translation Studies. Oxford, Oxford University Press. 


\section{Héctor Libreros Cortez y María del Pilar Ortiz Lovillo}

Entreculturas 11 (2021) pp. 85-104

Sánchez-Borzani, G. (2018): "La necesidad de profesionalización del traductor audiovisual en México”, en FernándezAcosta, L. R. (coord.): La profesión del traductor en México. Ciudad de México, UIC.

SES [en línea] (2019). https://www.educacionsuperior.sep. gob.mx/. [consulta: 11 de julio de 2020].

SECTUR [en línea] (2015): http://www.sectur.gob.mx/programas/gestion-de-destinos/productos-turisticos/tesoros-coloniales/san-miguel-de-allende/. [consulta: 20 de junio de 2020].

SHE. [en línea] (2018): https://www.harvardedu.org/. [consulta: 16 de junio de 2020].

Schmelkes, Sylvia (2008): “Creación y desarrollo inicial de las universidades interculturales en México: problemas, oportunidades, retos”, en Mato, D (coord.): Diversidad Cultural e Interculturalidad en Educación Superior: experiencias en América Latina. Caracas, UNESCO-IESALC.

Tricás, Mercedes (2003): Manual de traducción francés-castellano. Barcelona, Gedisa editorial.

TTTAC [en línea] (s.f.): http://tttac.com/maestrias/competencias-traductoras/. [consulta: 16 de junio de 2020].

$U A A$ [en línea] (2018). https://www.uaa.mx/portal/diplomados/diplomado-en-traduccion-e-interpretacion-del-idioma-ingles/. [consulta: 11 de julio de 2020].

$U A A$ [en línea] (s.f.): https://dgdp.uaa.mx/catalogo/ciencias_ sociales_humanidades/docencia_frances_espanol.pdf. [consulta: 22 de junio de 2020].

$U A B C$ [en línea] (2019): http://idiomas.uabc.mx/web/facultad-de-idiomas/inicio. [consulta: 12 de junio de 2020].

$U A B J O$ [en línea] (2019a): http://www.uabjo.mx/oferta-la-fiuabjo-nueva-maestria-en-lengua-literatura-y-traduccion. [consulta: 16 de junio de 2020].

UABJO [en línea] (2019b): http://www.uabjo.mx/abre-uabjomaestria-en-traduccion-e-interpretacion-de-lenguas-indigenas. [consulta: 16 de junio de 2020].

$U A B J O$ [en línea] (s.f.): http://www.idiomas.uabjo.mx/. [consulta:16 de junio de 2020].

$U A C H$ [en línea] (2020): https://cvc.cervantes.es/lengua/iulmyt/. [consulta: 22 de junio de 2020].

$U A D Y$ [en línea] (2020): http://www.educacion.uady.mx/index.php?seccion=programas\&enlace=leii. [consulta: 23 de junio de 2020].
UAEM [en línea] (s.f.): https://www.uaem.mx/organizacioninstitucional/unidades-academicas/institutos/cienciasde-la-educacion. [consulta: 22 de junio de 2020].

UAEMéx [en línea] (2015): http://denms.uaemex.mx/exporie ntavirtual/?courses=licenciado-en-lenguas. [consulta: 22 de junio de 2020].

$U A G$ [en línea] (2017): http://www.uag.mx/Universidad/Posgrado/Humanidades-Maestria-Traduccion-e-Interpretacion-Ingles-Espanol\#services. [consulta: 16 de junio de 2020].

UAGro [en línea] (s.f.): http://dae.uagro.mx/regweb/index. php?Opcion=ofeedupln. [consulta: 22 de junio de 2020].

UAIM [en línea]. (2020): http://uais.edu.mx/portal/. [consulta: 19 de junio de 2020].

UANL [en línea] (s.f.): http://www.filosofia.uanl.mx/. [consulta: 23 de junio de 2020].

UAQ-FLL [en línea] (2020): https://fll.uaq.mx/. [consulta: 23 de junio de 2020].

UAT [en línea] (s.f.): https://www.uat.edu.mx/SACD/DC/Paginas/Oferta-Educativa.aspx. [consulta: 23 de junio de 2020].

UAT-FADYCS [en línea] (2018): http://www.fadycs.uat.edu. $\mathrm{mx}$ /idiomaingles.html. [consulta: 23 de junio de 2020].

UATx [en línea] (2020): https://uatx.mx/oferta/licenciaturas/ ensenanza_de_lenguas. [consulta: 23 de junio de 2020].

$U A Z$ [en línea] (s.f.): http://lenguasextranjeras.uaz.edu.mx/. [consulta: 23 de junio de 2020].

UdeG [en línea] (2020): Recuperado de http://www.udg.mx/ es/oferta-academica/por-nivel. [consulta: 22 de junio de 2020].

UGTO [en línea] (2020): http://www.dcsh.ugto.mx/diplomados/diplomado-traduccion-espanol . [consulta: 11 de julio de 2020].

UIC [en línea] (s.f.): https://www.uic.mx/. [consulta: 11 de julio de 2020].

UIC [en línea] (s.f.): https://www.uic.mx/traduccion/diplomado-en-traduccion-especializada-e-interpretacion-profesional/. [consulta: 11 de julio de 2020].

UICEH [en línea] (2019): http://www.uiceh.edu.mx/. [ consulta: 19 de junio de 2020].

UICSLP [en línea] (2019): http://www.uicslp.edu.mx/paginas/carreras.html. [consulta: 19 de junio de 2020]. 


\section{LA FORMACIÓN EN TRADUCCIÓN EN MÉXICO}

Entreculturas 11 (2021) pp. 85-104

UIEG [en línea] (2020): http://www.uieg.edu.mx/asignaturaslc/. [consulta: 19 de junio de 2020].

UIEM [en línea] (s.f.): http://uiem.edomex.gob.mx/licenciatura-lengua-cultura .[consulta: 19 de junio de 2020].

UIEP [en línea] (s.f.): http://uiem.edomex.gob.mx/licenciatura-lengua-cultura. [consulta: 19 de junio de 2020].

UIET [en línea] (2015): http://www.uiet.edu.mx/palyc.php. [consulta: 19 de junio de 2020].

UIMM [en línea] (s.f.): http://uiem.edomex.gob.mx/licenciatura-lengua-cultura. [consulta: 19 de junio de 2020].

UIMQROO [en línea] (s.f.): http://uiem.edomex.gob.mx/licenciatura-lengua-cultura. [consulta: 19 de junio de 2020].

UJAT [en línea] (s.f.): http://www.archivos.ujat.mx/2019/ div-daea/Gu\%C3\%ADas\%20B\%C3\%A1sicas\%20-\%20 Nuevo\%20Ingreso/GuiaBasica\%20Idiomas.pdf. [consulta: 24 de junio de 2020].

UJAT [en línea] (2020): http://archivos.ujat.mx/2020/CELE/ Servicios\%20CELE\%20\%202020/MANUAL-DE-SERVICIO-CELE-2020.pdf. [consulta: 11 de julio de 2020].

UJED [en línea] (s.f.): http://escueladelenguas.ujed.mx/ledli/ plan-de-estudios/. [consulta: 24 de junio de 2020].

$U M A D$ [en línea] (s.f.): https://umad.edu.mx/maestrias/. [consulta: 16 de junio de 2020].

UNACAR [en línea] (s.f.): http://www.unacar.mx/f_educativas/lic_lengua_inglesa.html. [consulta: 22 de junio de 2020].

UNAM [en línea] (2019): http://www.filos.unam.mx/programas_academicos/. [consulta: 22 de junio de 2020].

UNAM [en línea] (2018): http://oferta.unam.mx/planestudios/traduccion-plan-de-estudios-17.pdf. [consulta: 16 de junio de 2020].

UNAM [en línea] (2012): https://enallt.unam.mx/index.php? categoria $=3 \&$ subcategoria $=19 \#$. [consulta: 11 de julio de 2020].

UNAM-ENES León [en línea] (2020): https://enes.unam.mx/ educon-uesma/diplomado-pedagogia-y-didactica-de-latraduccion6925195. [consulta: 11 de julio de 2020].

UNICACH [en línea] (2020): https://www.unicach.mx/addons/ofertaEducativa/pregrado/2020-Internacionales.pdf. [consulta: 24 de junio de 2020].
UNICH [en línea] (s.f.): https://www.unich.edu.mx/lengua-ycultura/. [ consulta: 19 de junio de 2020].

UPES [en línea] (2019): http://upes.edu.mx/portal/. [consulta: 11 de julio de 2020].

UQROO [en línea] (2019): http://www.uqroo.mx/intranet/ convocatorias/1456-diplomado-en-traduccion-inglesespaol-dtie-2020/. [consulta: 11 de julio de 2020].

UTECA [en línea] (2019): https://www.uteca.edu.mx/ofertaeducativa/. [consulta: 16 de junio de 2020].

$U V$ [en línea] (2020): https://www.uv.mx/. [consulta: 24 de junio de 2020].

UV [en línea] (2020): https://www.uv.mx/iie/general/diplomado-en-estudios-de-traduccion-e-interpretacion/. [consulta: 11 de julio de 2020].

UVI [en línea] (2020): https://www.uv.mx/uvi/. [consulta: 24 de junio de 2020].

Valdez-Gutiérrez, L. (2018): "El traductor en Baja California”, en Fernández Acosta, R. L (coord.) La profesión del traductor en México. Ciudad de México, UIC.

Villegas-Salas, L. I. (2019): "Ruta crítica profesionalizante: una experiencia pedagógica poslicenciatura en traducción”, Mutatis Mutandis. Revista Latinoamericana de Traducción, 12, 100-125.

Yin, Robert (2003): Case study research: Design and methods (3rd ed.). Thousand Oaks, CA, Sage. 